\title{
A modified Bläzka-type respirometer for the study of swimming metabolism in fishes having deep, laterally compressed bodies or unusual locomotor modes
}

\author{
J. R. Hove*, M. S. Gordon†§, P. W. WebBł ANd D. WeIHs \\ *Department of Aeronautics, California Institute of Technology, Pasadena, CA 91125, \\ U.S.A.; †Department of Organismic Biology, Ecology and Evolution, University of \\ California, Los Angeles, CA 90095-1606, U.S.A.; \$School of Natural Resources \\ and Environment, University of Michigan, Ann Arbor, MI 48109-1115, U.S.A. and \\ qDepartment of Aerospace Engineering, Technion, Haifa 32000, Israel
}

(Received 31 August 1999, Accepted 8 December 1999)

\begin{abstract}
A low volume (8.41), rectangular (cross-section) respirometer modified from a Bläzka-type coaxial circuit, which provides rectilinear flow at speeds up to $0.36 \mathrm{~m} \mathrm{~s}^{-1}$, is described.

(C) 2000 The Fisheries Society of the British Isles
\end{abstract}

Key words: Bläzka respirometer; fish swimming; oxygen consumption.

By allowing physiological measurements on relatively unrestrained animals, the introduction of swimming respirometers has revolutionized aquatic performance studies (Fry \& Hart, 1948). A number of water tunnel respirometer types exist (Cech, 1990; Lucas et al., 1993), but the most widely used configurations are patterned after two designs: Brett's (1964) annular tunnel and the Bläzka et al.'s (1960) coaxial circuit. Brett-type tunnels usually have better controlled, more uniform flow conditions since they use low-angle bends, fairing plates and an elongated upstream return section to minimize turbulence and vorticity. The Bläzka design (concentric tubes) has inherently more flow irregularity but can have much lower volume (lacking an extended return circuit), a great advantage in respirometric studies when studying small fishes or those having low metabolic rates.

Metabolic studies of morphologically diverse groups of fishes require flexibility in flume design. In recent years, researchers have produced a number of variations for specific purposes. Modifications to Brett-type tunnels include: tilting flumes (Priede \& Holliday, 1980); automated chambers (Steffensen et al., 1984); large-scale flumes (Vogel \& LaBarbera, 1978; Graham et al., 1990); and long-term monitoring systems (Gehrke et al., 1990). Refinements to Bläzka-type respirometers include accommodations for large fishes (Smith \& Newcomb, 1970) or small fishes (Kaufmann, 1990) and for high-speed swimmers (Hunter \& Zweifel, 1971).

As with any respirometric design, care must be taken when selecting the species to be used in swimming energetics experiments. Fishes with non-fusiform body designs, particularly those which are laterally compressed with unusually deep bodies (e.g. various members of the Lampridae, Chaetodontidae, Cichlidae, Ephippididae) can present dimensional problems for respirometric studies. Deep-bodied fishes have most of their cross-sectional area distributed in a vertical plane with little expansion in the horizontal. Therefore a chamber of expanded dimensions in the vertical plane is required to prevent interactions between the fish and the boundary layers near the top and bottom walls of the flume. Such interactions can drastically affect the swimming performance and energy expenditure of the test subject (Pope \& Harper, 1966).

§Author to whom correspondence should be addressed. Tel.: (310) 825-4579; fax: (310) 206-3987; email: msgordon@ucla.edu 
In addition to morphological constraints, some fishes swim with unusual body postures. Both Atlantic mackerel Scomber scombrus L. (He \& Wardle, 1986) and steelhead trout Oncorhynchus mykiss (Walbaum) (Webb, 1993) demonstrate a head up (positive angle of attack) body posture at low swimming speeds. Webb (1993) also described a head down (negative angle of attack) swimming posture in bluegill Lepomis macrochirus Rafinesque, particularly at $<1$ body length $\mathrm{s}^{-1}$ swimming speeds. A recent examination of the swimming behaviour of individual South American freshwater electric fishes (Teleostei: Gymnotiformes) also revealed a significant negative angle of attack in these fishes (J. R. Hove, unpubl. data). These studies demonstrate that body tilting may be a common behaviour in a number of fish groups, particularly at low speeds. A specially designed swimming chamber for measurements of swimming metabolism in such groups is therefore desirable. This paper describes such a system, modified from the basic Bläzka design to accommodate fishes or other aquatic organisms that show these unusual body designs or swimming behaviours. The design has proved to be adequate for testing fishes $\leqslant c .12 \mathrm{~cm} L_{\mathrm{T}}$ swimming at low relative speeds $\left(\sim 3 L_{\mathrm{T}} \mathrm{s}^{-1}\right)$. If a greater range of relative swimming speeds is necessary, fish of lesser total length should be used or a system of proportionally greater dimensions could be fabricated, keeping in mind the limitations for measuring oxygen consumption in greater volumes of water.

Extremely deep-bodied bauplans or vertical tilting behaviours suggest two central design constraints: (i) the need for expansion of the flume working section in the vertical plane to minimize adverse boundary layer interactions; and (ii) the need to minimize water volumes in the respirometers since many of these fishes have lower body mass per unit length than is typical for fusiform fishes.

Another design consideration relates to the types of drive systems necessary to move water through such an apparatus. Traditional circular or square working sections allow a single propeller or water jet to do this task. A very large, uni-propulsor flume described by Webb (1998) uses multiple turning vanes for flow in vertically extended crosssections. Its size allows for behavioural and biomechanical measurements at flow speeds $\leqslant 1 \mathrm{~m} \mathrm{~s}^{-1}$. Unfortunately such a design requires substantial water volume preventing its use for respirometry. Alternatively, multiple propellers can be used to provide uniform flows across the cross-section of the swimming chamber. This design strategy also requires an integrated control module to drive those propellers synchronously. Finally, it is desirable to use non-corroding materials for the flume construction, allowing it to be useful for either marine or freshwater applications.

The Bläzka-style flume [Fig. 1(a)] had an inner circuit measuring $8.1 \times 15.4 \times 29.3 \mathrm{~cm}$ (width $\times$ height $\times$ length - inner dimensions) with the actual swimming area (observation section), delineated by flow straighteners, measuring $8.1 \times 15.4 \times 15.1 \mathrm{~cm}$. The outer chamber is $12.2 \times 20.3 \times 34.2 \mathrm{~cm}$ yielding a system with a total volume of $c .8 \cdot 41$. The inner circuit has a removable trap door $(6.5 \times 14.3 \mathrm{~cm})$ milled to fit flush against the plexiglass ceiling. A matching opening on the outer rectangular circuit is aligned with the inner trap door. This outer loading bay is equipped with an O-ring and stainless steel wingnuts to form a watertight seal, which prevents mixture of flume water with water in the temperature bath. The bay openings allow experimental fishes to be loaded and removed with minimal disturbance to the rest of the respirometer and also to expedite removal of air bubbles entrained in the system. Four tubing ports pass through the outer circuit, providing pathways for water sampling, reoxygenation and temperature monitoring.

The geometry of a Bläzka respirometer with a rectangular cross-section provides a number of opportunities for turbulent flow. Several measures were taken to improve this situation in order to get the least turbulent, most rectilinear flow profiles in the working section. Firstly, $1 \cdot 28-\mathrm{cm}$ acrylic fairing bars with right-angled triangular cross-sections were fitted in all of the joints of the outer Bläzka circuit [j, Fig. 1(a)], providing a stretched octagonal cross-section and smoother flow. Although a smooth elliptical cross-section would have produced the least turbulent flow, the cost of bending and milling plexiglass into that geometry was prohibitive. It was decided that a rectangular design with fairing bars was still hydrodynamically acceptable while being more cost effective. Secondly, the upstream end cap [c, Fig. 1(a) and (b)] consisted of two moulded 


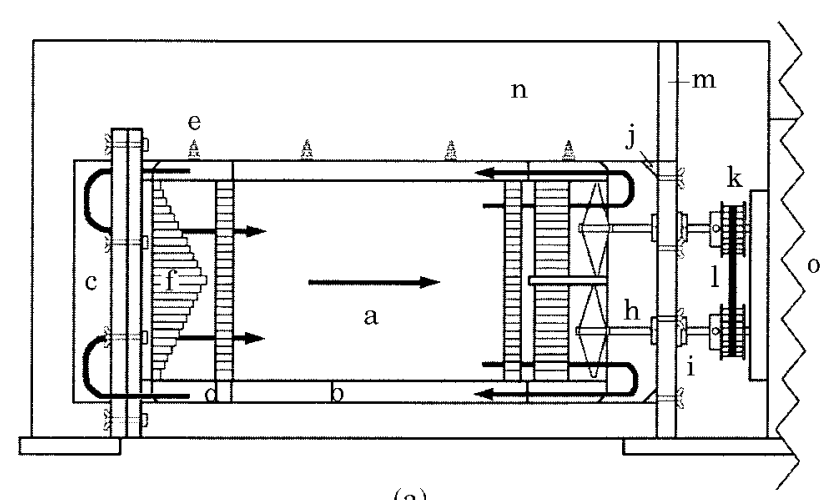

(a)

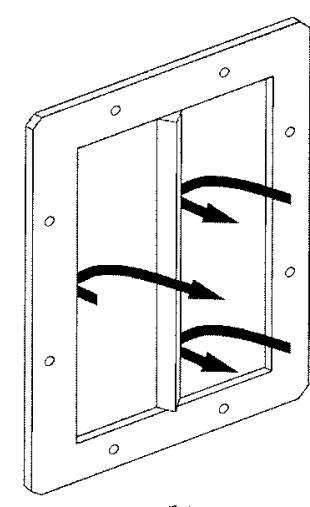

(b)

FIG. 1. (a) Schematic of the lateral view of the flume portion of respirometer. a, Inner circuit; b, outer circuit; c, hemicylindrical endcaps; d, straightening vanes; e, tubing ports; f, primary flow straightener; g, propellers; h, shaft; i, shaft seal; j, fairing bar; k, timing gear; 1 , timing belt; m, retaining wall; $n$, temperature bath; $\mathrm{o}$, drive section. Arrows indicate direction of water flow. (b) Diagram of upstream endcap for respirometer. Two milled, hemispherical Plexiglas halves redirect water flow (arrows) from outer circuit to inner swimming chamber.

plexiglass hemicylinders that served to redirect the water $180^{\circ}$ from the outer circuit to the inner observation section with a minimum of vorticity. A series of $5 \mathrm{~cm}$ long, end-tapered straightening vanes [d, Fig. 1(a)] were positioned between the inner and outer Bläzka circuits at both the upstream and downstream ends. The vanes were fixed to the exterior of the inner circuit, on either side, at the top, centre and bottom of that circuit (six vanes on each end). These served largely to dissipate the substantial vortical motions imparted on the water by the two spinning propellers [g, Fig. 1(a)]. In addition, they fixed the position of the inner circuit with respect to the outer circuit. Four flow straighteners were installed within the inner circuit, two upstream of the observation section and two downstream. The last of these also helped break up water rotation imparted by the propellers (Vogel \& LaBarbera, 1978). The first flow straightener (farthest upstream) [f, Fig. 1(a)] was made of $0 \cdot 6-\mathrm{cm}$ diameter soda straws of varying lengths designed to utilize friction to slow water in the centre of the flume to yield a rectilinear flow profile. The second and third straighteners were made of $1.8-\mathrm{cm}$ wide plastic honeycomb $(0.6 \mathrm{~cm}$ circular bore) with the last being $2.5 \mathrm{~cm}$ wide $(0.9 \mathrm{~cm}$ circular bore $)$.

The dual drive system consisted of two $7 \cdot 6-\mathrm{cm}$ diameter, bronze model boat propellers (Dumas Products) having left-hand twist and $5 \mathrm{~cm}$ pitch. Each was sealed with Krylon to avoid leaching of copper and tin into the water. The propellers were both shrouded within the inner Bläzka circuit and mounted one above the other on $0 \cdot 48$-cm diameter stainless steel shafts. The shafts led through two sets of watertight seals (teflon-graphite composite) and each was fitted with a timing gear. A rubber timing belt allowed for synchronous operation of the two props. The lower of the two shafts extended into a 0.25-hp, 90-V DC Bodine motor controlled by a Minarik MM311U speed control (Fig. 2). The lower shaft was also fitted with a $9 \cdot 5-\mathrm{cm}, 60$-tooth, 16-diametric pitch steel gear and a magnetic pickup (Danaher Controls, Model 54ZT) which together served as a tachometer. Resultant rpms were displayed on a digital LCD rate indicator powered by a $12-\mathrm{V}$ DC power supply.

The most critical concern for proper flume function using two propellers is the precise alignment of the shafts within the flume. The teflon-graphite composite seals not only prevented leakage of water into or out of the respiratory chamber but also served as a second fixed point (in addition to the motor insertion) to help maintain exact propeller alignments. Near perfect alignment was necessary to prevent any unnecessary friction between the shaft and seal that would: (i) affect propeller speed and consequently, water velocity in the swimming chamber; and (ii) quickly wear out the seals leading to leakage. To facilitate the maintenance of the alignment, Plexiglas guides were installed into the 


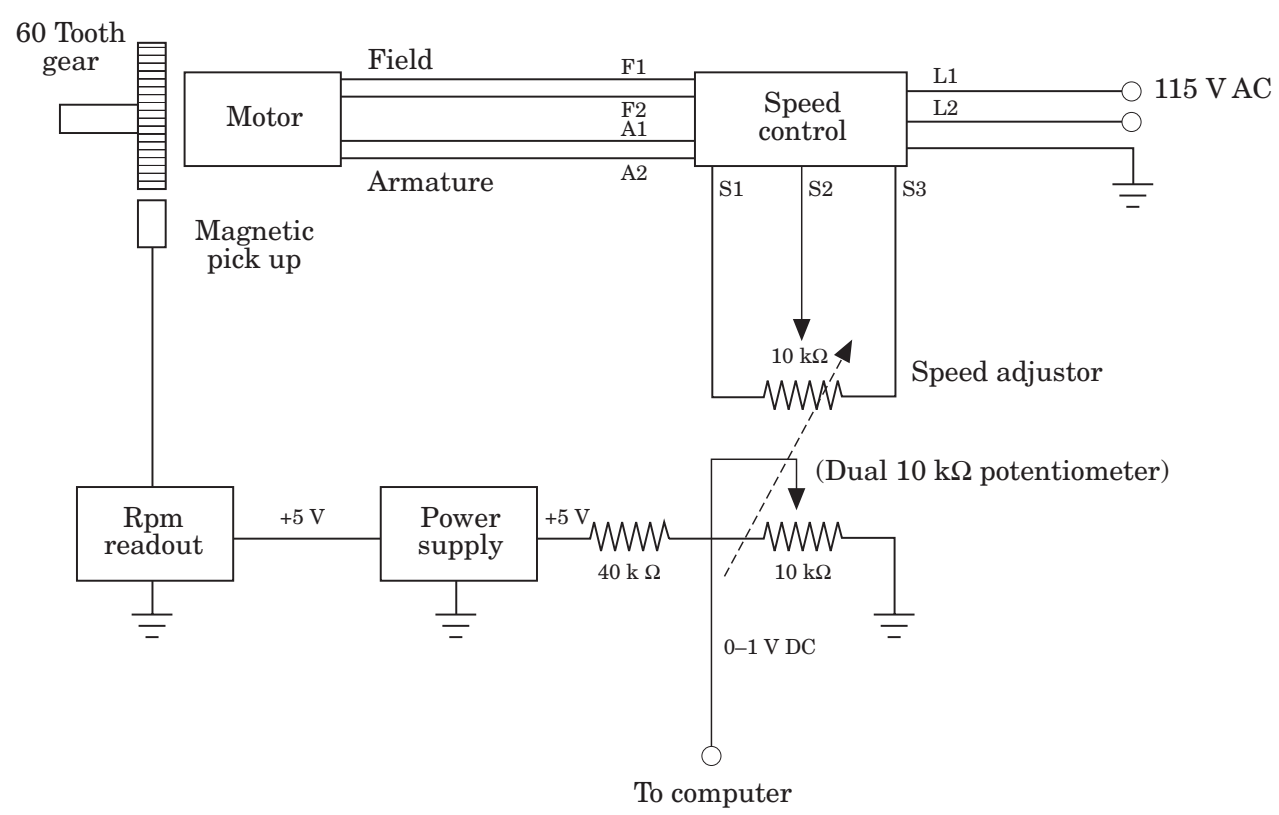

FIG. 2. Electrical schematic of the drive portion of respirometer.

floor of the temperature control tank preventing any respirometer movement normal to the prop shafts. Finally, the downstream end cap of the outer Bläzka circuit was semi-permanently mounted into the temperature bath retaining wall [m, Fig. 1(a)] to prevent accidental jostling of the flume during experimental manipulations that might result in misalignment of the shafts. This endplate, through which the propellor shafts ran, possessed a carefully milled groove containing a rubber O-ring and was fastened to the outer circuit with stainless steel wingnuts. This design allowed both the inner and outer circuits to be removed from the temperature bath if the need arose leaving the shaft/propeller assemblies in fixed positions.

Both the inner and outer rectangular circuits of the flume itself and end caps were fabricated from 0.64-cm thick transparent Plexiglas. The temperature control tank and fairing bars were made of $1 \cdot 28-\mathrm{cm}$ thick transparent Plexiglas. The drive system and all electronic control components are sealed in an adjoining water-resistant housing made of $0 \cdot 64-\mathrm{cm}$ black opaque Plexiglas. Both flume and drive sections are mounted on a $1.28-\mathrm{cm}$ thick Plexiglas base.

Propeller rotations were controlled with high precision $( \pm 1 \mathrm{rpm})$ over a full range of speeds. At rates $>c$. $1800 \mathrm{rpms}$ the propellers produced cavitation bubbles numerous enough to warrant concern over fish stress in addition to preventing accurate respirometry. A high speed variable resistor (potentiometer) was adjusted down to yield a controlled output range of $0-1800 \mathrm{rpms}$, keeping flow velocities $\left(0-36 \mathrm{~cm} \mathrm{~s}^{-1}\right.$ range) below the critical level for system cavitation.

Two major concerns in flow tank experiments are: (i) the presence and magnitude of turbulence in the working section; and (ii) the increasing thickness of boundary layers along the walls of a flume, particularly at downstream locations (Vogel \& LaBarbera, 1978). Flow visualization using videotaped sequences of timed dye injections at nine discreet points in the cross-sectional area of the observation section allowed these problems to be quantified generally. Using this technique, water velocities measured $1 \mathrm{~cm}$ from the walls, even at the downstream end of the observations section, were not significantly different from those in the centre of the flume $(P>0 \cdot 9$, ANOVA).

Water velocities were measured over 14 calibration speeds and the cross-sectional flow profile was satisfactorily rectilinear (Fig. 3). Dye trails revealed no significant vorticity or 


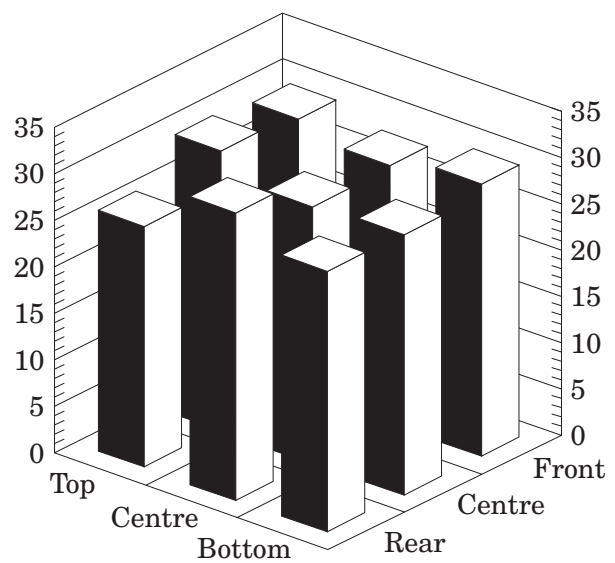

FIG. 3. Bar graph depicting cross-sectional flow profile in the observation section of the inner Bläzka circuit at $28 \mathrm{~cm} \mathrm{~s}^{-1}$. Bar height indicates local water velocities $\left(\mathrm{cm} \mathrm{s}^{-1}\right)$ in nine quadrants and demonstrates relative profile uniformity. These data are representative of other profiles across all speeds.

dead spots in the observation section of the flume over low or intermediate speeds. Only at the highest speeds $\left(>30 \mathrm{~cm} \mathrm{~s}^{-1}\right)$ did the dye streams not conform to the previously observed uniform streamlines. At these high flow speeds, dye streams along the top of the chamber were drawn downward toward the centre of the chamber over the last $2 \mathrm{~cm}$ of the working section. This could have been caused by complicated interactions between the wakes of the two propellers at such elevated velocities and their close proximity to the downstream flow straighteners $(c .0 \cdot 5 \mathrm{~cm})$. This flow pattern did not appear to have any influence on test fish swimming patterns as they avoided that flow straightener except when exhausted.

Response time of the system to oxygen depletion was tested also. This is necessary as failure to account for significant lag between organismal and system responses, even in closed systems, can lead to serious errors (Niimi, 1978). A 15-ml volume of water was chemically stripped of $\mathrm{O}_{2}$ using $\mathrm{NaSO}_{3}(250 \mathrm{mg})$ and injected into the flume via a tubing port. Minimum detection time for the onset of $\mathrm{O}_{2}$ depression was $16 \mathrm{~s}$, small enough that no mathematical compensation was necessary. The lack of significant flow irregularities in the working section, as estimated by the flow visualization techniques described above, and the high turnover rate undoubtedly contributed to the low lag time observed.

We thank R. Klufas and M. Eng for the construction of the mechanical and electronic modules respectively, and E. Ron and L. Teschmacher for calibrating the apparatus. This work was partially funded by the UCLA Department of Biology, a Sigma Xi Grant-In-Aid of Research and ONR AASERT grant no. N00014-97-1-0619 to M.S.G.

\section{References}

Bläzka, P., Volf, M. \& Cepela, M. (1960). A new type of respirometer for the determination of the metabolism of fish in an active state. Physiologia Bohemoslovenica 9, 553-560.

Brett, J. R. (1964). The respiratory metabolism and swimming performance of young sockeye salmon. Journal of the Fisheries Research Board of Canada 21, 1183-1226.

Cech, J. J. (1990). Respirometry. In Methods for Fish Biology (Schreck, C. B. \& Moyle, P. B., eds), pp. 335-362. Bethesda, MD: American Fisheries Society.

Fry, F. E. \& Hart, J. S. (1948). Cruising speed of goldfish in relation to water temperature. Journal of the Fisheries Research Board of Canada 7, 169-175.

Gehrke, P. C., Fidler, L. E., Mense, D. C. \& Randall, D. J. (1990). A respirometer with controlled water quality and computerized data acquisition of experiments with swimming fish. Fish Physiology and Biochemistry 8, 61-67. 
Graham, J. B., Dewar, H., Lai, N. C., Lowell, W. R. \& Arce, S. M. (1990). Aspects of shark swimming performance determined using a large water tunnel. Journal of Experimental Biology 151, $175-192$

He, P. \& Wardle, C. S. (1986). Tilting behaviour of the Atlantic mackerel, Scomber scombrus, at low swimming speeds. Journal of Fish Biology 29 (Suppl. A), 223-232.

Hunter, J. R. \& Zweifel, J. R. (1971). Swimming speed, tail beat frequency, tail beat amplitude, and size in jack mackerel, Trachurus symmetricus, and other fishes. Fishery Bulletin 69, 253-266.

Kaufmann, R. (1990). Respiratory cost of swimming in larval and juvenile cyprinids. Journal of Experimental Biology 150, 343-366.

Lucas, M. C., Johnstone, A. D. F. \& Tang, J. (1993). An annular respirometer for measuring aerobic metabolic rates of large, schooling fishes. Journal of Experimental Biology 175, 325-331.

Niimi, A. J. (1978). Lag adjustment between estimated and actual physiological responses conducted in flow-through systems. Journal of the Fisheries Research Board of Canada 35, 1265-1269.

Pope, A. \& Harper, J. J. (1966). Low Speed Wind Tunnel Testing. New York: John Wiley.

Priede, I. G. \& Holliday, F. G. T. (1980). The use of a new tilting tunnel respirometer to investigate some aspects of metabolism and swimming activity of the plaice (Pleuronectes platessa L.). Journal of Experimental Biology 85, 295-309.

Smith, L. S. \& Newcomb, T. W. (1970). A modified version of the Bläzka respirometer and exercise chamber for large fish. Journal of the Fisheries Research Board of Canada 27, 1321-1324.

Steffensen, J. F., Johansen, K. \& Bushnell, P. G. (1984). An automated swimming respirometer. Comparative Biochemistry and Physiology A, Comparative Physiology 79, 437-440.

Vogel, S. \& LaBarbera, M. (1978). Simple flow tanks for research and teaching. Bioscience 28, 638-643.

Webb, P. W. (1993). The effect of solid and porous channel walls on steady swimming of steelhead trout Oncorhynchus mykiss. Journal of Experimental Biology 178, 97-108.

Webb, P. W. (1998). Entrainment of the river chub, Nocomis micropogon, and smallmouth bass, Micropterus dolomieui, on cylinders. Journal of Experimental Biology 201, 2403-2412. 